\title{
Advances in Vestibular schwannoma microneurosurgery: Improving Results with New Technologies (2019) Editors: L. Mastronardi, T. Fukushima A. Campione 174 pages, illustrated ISBN: 9783030031671 Springer Publishers
}

\author{
Morten Lund-Johansen ${ }^{1}$ (i) \\ Received: 26 July 2019 / Accepted: 31 July 2019/Published online: 9 August 2019 \\ (C) Springer-Verlag GmbH Austria, part of Springer Nature 2019
}

The book presents the practice of a renowned neurosurgical group in their management of patients with vestibular schwannoma. It contains twenty chapters divided into four sections (General aspects, Surgical technique, New technologies, Projects in progress) plus concluding remarks at the end, and in addition has a web-based video section (not subject to this review).

The first section contains a chapter on treatment options where the authors conclude that surgery is the prime management option in the vast majority of diagnosed cases. This does not necessarily adhere to worldwide trends where a majority of cases either receive watchful waiting or radiosurgery and the authors do not quote recent literature comparing treatment options, but instead select references that agree with their personal view. The section on surgical technique adequately describes positioning, approaches and instruments presented together with illustrations and intraoperative photos, most of which are reproduced from earlier literature. The authors present their own series of 160 cases in a separate chapter, showing $60.6 \%$ total resection rates and good hearing and facial nerve outcomes. In the section about new technologies, there are two chapters on electrophysiology; dealing with the 7 th and 8th nerves, respectively. They provide instructive information about applied techniques and prognostic threshold values. I missed illustrations of their setup, and also would have liked to read about recent development of continuous facial nerve stimulation (FREEMAP) [1] although this may not be part of the authors' armamentarium. At the end of the section, they review the important issue of dural closure, and finally they discuss the principle of four-hand surgery. Both chapters provide valuable information to the reader. In the final section, the authors discuss topics such as peroperative papaverine administration, endoscopy, bone closure with cement, aspirin use, and facial nerve detection by diffusion tensor imaging (the latter unfortunately without any image). They finally discuss post-radiosurgery tumor resections and conclude that some of these tend to be difficult due to adhesions.

The book is a manual about surgery for vestibular schwannoma and should be read as such. At the end, the authors summarize their findings. For most patients, they argue against wait-and scan or radiosurgery as primary treatment options. They conclude that early surgery is usually the preferred treatment, and that such a strategy leads to a better prognosis in particular regarding hearing. Let us hope that the future will bring studies to elucidate us with a high level of evidence as to whether or not their conclusion is valid for those of us treating patients with vestibular schwannoma.

\section{Reference}

1. Nakatomi H, Miyazaki H, Tanaka M, Kin T, Yoshino M, Oyama H, Usui M, Moriyama H, Kojima H, Kaga K, Saito N (2015) Improved preservation of function during acoustic neuroma surgery. $\mathrm{J}$ Neurosurg 122(1):24-33. https://doi.org/10.3171/2014.8. JNS132525

Publisher's note Springer Nature remains neutral with regard to jurisdictional claims in published maps and institutional affiliations.

Morten Lund-Johansen

mljo@helse-bergen.no

1 Helse Bergen, Haukeland universitetssjukehus, Nevrokirurgisk Avdeling, Postboks 1400, 5021 Bergen, Norway 